Dhaka Univ. J. Biol. Sci. 21(1): 55-65, 2012 (January)

\title{
DISTRIBUTION OF HELMINTH PARASITES IN SIZE GROUPS AND ORGANS OF HILSA SHAD, TENUALOSA ILISHA
}

\author{
Joseph D'Silva ${ }^{1}$, Aminul Islam Bhuiyan* And Glenn A. BRistow² \\ Department of Zoology, University of Dhaka, Dhaka-1000, Bangladesh
}

Key words: Hilsa, Parasites, Organ, Sex, Size

\begin{abstract}
Demographic parameters such as prevalence, intensity, abundance etc. of the component parasites of hilsa (Tenualosa ilisha) collected from 11 sites under 3 different habitats all over Bangladesh were calculated as a function of host size, sex and organ of infection. Organ preference of component parasite species did not show any variation in the hilsa collected from the three ecological habitats. All the trematodes were found exclusively in cardiac stomach and intestine. Nematodes were less organ specific. Abundance of total parasites in cardiac stomach and intestine were not significantly different from each other but that of stomach and mesenteries were significantly different from each other and from cardiac stomach or mesentery. In freshwater hilsa differences between most of the lower length groups were not significant $(p>0.05)$. In brackish water hilsa parasite burden were significantly different between length groups. In marine hilsa mean parasites burden in different length classes were not significant $(\mathrm{p}>$ $0.05)$.
\end{abstract}

\section{Introduction}

The helminth parasites of a migratory fish, Tenualosa ilisha were investigated to determine if there was a difference in their composition between freshwater, brackish and salt water. The hilsa is resident fish in the Bay of Bengal. During spawning, it migrates to upstream. The migration begins in the monsoon season around the month of May. Fish return to the Bay in December. The hypothesis was that the hilsa might lose some parasites and acquire others during its migration and the frequency distribution of the parasites would be related to sex and size of the host fish. This aspect of the hilsa parasites has not been reported although the parasites of hilsa have been reported by several workers ${ }^{(1-5)}$.

Frequency of infestation and distribution of parasites within different organs of the fishes is influenced by age and diet, abundance of parasites within the fish and fish abundance( ${ }^{(6)}$.

${ }^{*}$ Corresponding author. <aminul_islam89@yahoo.com>.

${ }^{1}$ Department of Biology, Norfolk State University, Norfolk, Virginia, 23321, USA.

2Department of Biology, Bergen University, Allegaten 41, N-5007 Bergen, Norway. 
In the present work we have analysed the epidemiology of parasitism as function of the size, sexes and organs of individual hosts. The model we studied is represented by the helminth parasitic in community of hilsa fish collected from all over Bangladesh. We used prevalence and intensity as defined by Margolis et al.(7) to evaluate the demography of parasitism because we think these are the most reliable parameters reflecting the populational aspects of parasite - host relationships. Present aim is to compare the relationships between prevalence - intensity and host size-organ in a single species parasitizing the same host.

\section{Materials and Methods}

The host fish, Tenualosa ilisha were collected from three different ecological habitats of Bangladesh waters like river (Chandpur $23^{\circ} 14.40 \mathrm{~N} 90^{\circ} 40.73 \mathrm{E}, \mathrm{n}=732$, Aricha $23^{\circ} 46.10$ N 89॰46.83 E, $n=624$, Paksey $24^{\circ} 04.46$ N 98 $02.15 \mathrm{E}, \mathrm{n}=99$ Sherpur $24^{\circ} 37.65 \mathrm{~N} 91^{\circ} 40.82 \mathrm{E}$,

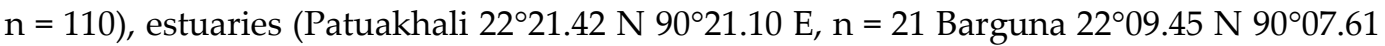

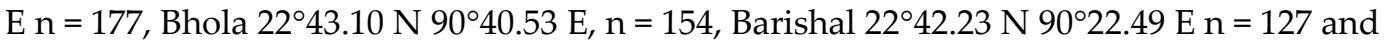

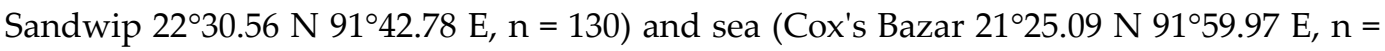
296 and Kuakata $21^{\circ} 48.97 \mathrm{~N} 90^{\circ} 07.32 \mathrm{E}, \mathrm{n}=197$ ). A total of 2667 fish were collected from January, 1997 to December, 1999. Prevalence, intensity and abundance were calculated according to Margolis et al.(7) and component parasites as of Bush et al.(8).

The viscera of the fish were removed individually and put in $10 \%$ formalin in polyethylene bags with a label inside. Before they were dissected the weight, length and sex of each fish were recorded. The organs were then brought to the Parasitology laboratory, Department of Zoology, University of Dhaka, Dhaka, Bangladesh. Extensive search was made for helminth parasites infecting the fish using Leica Zoom 2000 Dissecting Microscope. Cardiac stomach, pyloric ceaca, stomach, intestine and mesenteries were separated, placed in Petri dishes and searched. All the parasites from each organ were sorted, cleaned and counted. They were preserved in $70 \%$ alcohol. Berland's ${ }^{(9)}$ methods were used for staining and mounting.

The T. ilisha studied for endoparasites was between 17.2 and $58 \mathrm{~cm}$ in length. The fish were divided into nine arbitrary groups as follows: 1st gr $\rightarrow 15-20 \mathrm{~cm}$; 2nd gr $\rightarrow 20$ $25 \mathrm{~cm}$; 3rd gr $\rightarrow 25-30 \mathrm{~cm}$; 4th gr $\rightarrow 30-35 \mathrm{~cm}$; 5 th gr $\rightarrow 35-40 \mathrm{~cm}$; 6 th gr $\rightarrow 40-45 \mathrm{~cm}$; 7th gr $\rightarrow 45-50 \mathrm{~cm}$; 8th gr $\rightarrow 50-55 \mathrm{~cm}$; and 9th gr $\rightarrow 55-60 \mathrm{~cm}$.

As parasites counts were not normally distributed, nonparametric ANOVA using ranked scores (SAS PROC GLM procedure) was used. A two factor ANOVA and DMRT were done to compare roles of habitats, sex and organ of host in building parasite load. Square root transformation of parasite numbers was done to bring frequency distribution close to normal for ANOVA. All statistical tests were done by SAS version 6.(10) Only the data on component parasites were used in calculation. 


\section{Results and Discussion}

Tenualosa ilisha has a rich and diverse parasite fauna. Altogether 14 species/genus of endohelminths have been collected and identified from alimentary canal and associated organs (mesenteries and caeca) of hilsa shad, Tenualosa ilisha. These are five trematodes: Aphanurus stossichi, Faustula brevichrus, F. gangetica, F. ilishii, Lecithaster indicus; two cestodes: Ilisha parthenogenetica (plerocercoid) and Otobothrium ilisha (plerocercoid); five nematodes: Goezia bangladeshi (adult and larvae), Camallanus sp. (larvae), Porrocaecum sp. (larvae), Capillaria sp. (larvae) and Hysterothylacium sp. (larvae) and two acanthocephalans: Acanthosentis indica and A. hilsai. All 14 were present in both freshwater, brackish and salt water fish, indicating a remarkable spatial stability. Of the 14 parasites only 6 had the status of component parasite (prevalence above 10\%). These are Aphanurus stossichi, Lecithaster indicus, Faustula spp., Ilisha parthenogenetica, Goezia bangladeshi and Acanthosentis spp.

The organ and sites of infection by the gut helminths of $T$. ilisha are shown in Table 1 . Some species were found specifically in an organ while others were found in more than one organ.

Table 1. Organ of infection by parasites of T. ilisha in Bangladesh.

\begin{tabular}{|c|c|c|c|}
\hline \multirow{2}{*}{ Group } & \multirow{2}{*}{ Parasites } & \multicolumn{2}{|c|}{ Organs } \\
\hline & & Mainly found & Occasionally found \\
\hline \multirow[t]{5}{*}{ Trematoda } & Aphanurus stossichi & Cardiac stomach & Stomach \\
\hline & Faustula brevichrus & Intestine & Cardic stomach/stomach \\
\hline & F. gangetica & $"$ & $"$ \\
\hline & F. ilishii & $"$ & $"$ \\
\hline & Lecithaster indicus & $"$ & $"$ \\
\hline \multirow[t]{2}{*}{ Cestoda } & $\begin{array}{l}\text { Ilisha parthenogenetica } \\
\text { (plerocercoid) }\end{array}$ & $"$ & Stomach \\
\hline & Otobothrium ilisha (plerocercoid) & Intestine/intestinal caeca & \\
\hline \multirow[t]{5}{*}{ Nematoda } & $\begin{array}{l}\text { Goezia bangladeshi (adult \& } \\
\text { larvae) }\end{array}$ & Intestine/stomach & Mesentery \\
\hline & Camallanus sp. (larvae) & $"$ & \\
\hline & Porrocaecum sp. (larvae) & $"$ & \\
\hline & Capillaria sp. (larvae) & $"$ & \\
\hline & Hysterothylacium sp. (larvae) & $"$ & \\
\hline \multirow[t]{2}{*}{ Acanthocephala } & Acanthosentis indica & $\begin{array}{l}\text { Cardic stomach/ } \\
\text { stomach }\end{array}$ & \\
\hline & A. hilsai & Intestine/stomach & \\
\hline
\end{tabular}

The cardiac stomach and intestine were the most infected organs. Most of the parasites were found mainly in intestine and cardiac stomach. Stomach was very occasionally infected by Goezia bangladeshi larvae. Some plerocercoids of Otobothrium ilisha were found in the intestinal caeca. 
Abundance of component parasites at each organ is presented in the Fig. 1. Faustula spp. and L. indicus were found exclusively inhabiting in intestine. Some $97.8 \%$ of Faustula spp. and $98.1 \%$ of L. indicus were recovered from intestine. Only a few of them were found in other parts of alimentary tract. On the other hand A. stossichi was found inhabiting in the whole gut with higher prevalence in cardiac stomach. Free larval stages of G. bangladeshi were more abundantly found in intestine (89.3\%), and only a few of them were recovered from cardiac stomach and intestine too. But encysted G. bangladeshi
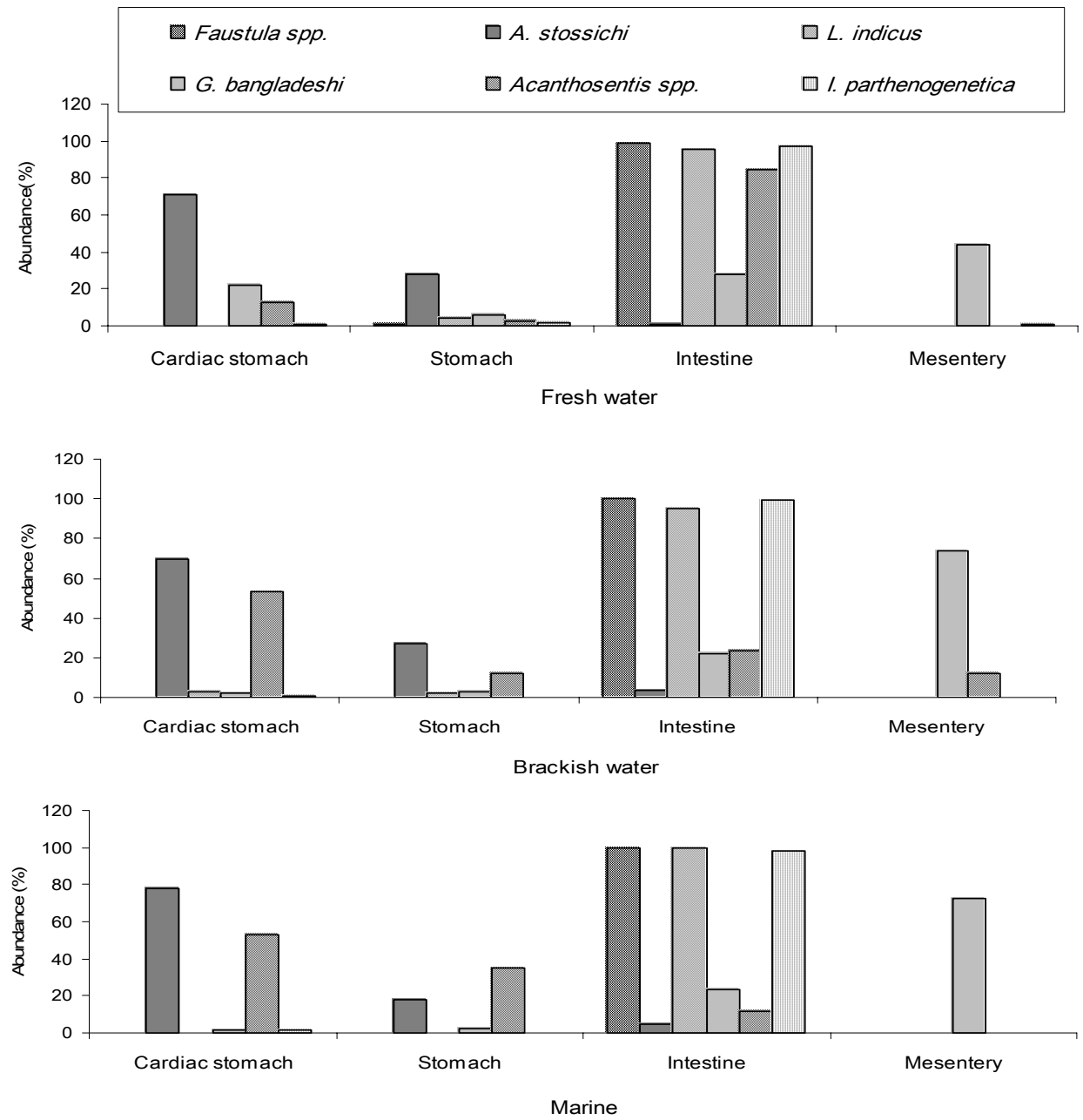

Fig. 1. Abundance (\%) of component parasites in the organs of infection.

was found exclusively in mesenteries around gut. Acanthosentis spp. was found both in cardiac stomach and intestine with almost equal prevalence, a few of them were found in stomach. Plerocercoid larva of I. parthenogenetica was mainly found in intestine. Cardiac stomach and intestine were found to be more preferred organs to most of the helminths. 
Organ preference of component parasite species did not show any variation in the hilsa collected from the three ecological habitats from where the host fishes were collected. Organ preference of a parasite was almost same in three habitats. All the trematodes were found exclusively in cardiac stomach and intestine. Nematodes were less organ specific.

Abundance of total parasites in cardiac stomach and intestine were not significantly ( $p>0.05$ ) different from each other but that of stomach and mesenteries were significantly different from each other and from cardiac stomach or mesentery (Table 2).

Table 2. Comparison of mean parasite load in organs of T. ilisha (ANOVA).

\begin{tabular}{ll}
\hline Organs & Means \\
\hline Cardiac stomach & $3.410 \mathrm{a}^{*}$ \\
Stomach & $2.734 \mathrm{~b}$ \\
Intestine & $3.368 \mathrm{a}$ \\
Mesentery & $2.125 \mathrm{c}$ \\
\hline
\end{tabular}

${ }^{*}$ Means followed by the same letter are not significantly different at $5 \%$ level of significance.

The organ most often infected is the intestine, which harboured up to 12 different helminths. The highest number of different parasite species was recorded from the intestine of $T$. ilisha. The richest parasite community of helminths occurred in the intestine in the European eel, Anguilla anguilla(11). The intestine is a common organ of infestation for most of the parasites.

Fishes were divided into nine arbitrary classes according to total length to see the relation of component parasites with the size of host fish, T. ilisha. Figs 2 and 3 show the prevalence and intensity of component parasites of $T$. ilisha in relation to host length categories as a measure of host size. In brackish water and in marine samples there were no T. ilisha measuring between 15 and $20 \mathrm{~cm}$ total lengths (1st gr).

This digenea was more prevalently present in higher size classes (5th - 8th gr) of freshwater hilsa. In brackish water hilsa prevalence of Faustula spp. did not vary widely between size classes. Prevalence was high in all classes (87.5 - 100\%) but mean intensities were higher in larger size classes (5th - 9th gr). The prevalence and intensity in marine water hilsa showed the same pattern like that of brackish water sample. Prevalence ranged between $88.24-100 \%$ and mean intensities were higher in larger size classes like brackish water sample. 

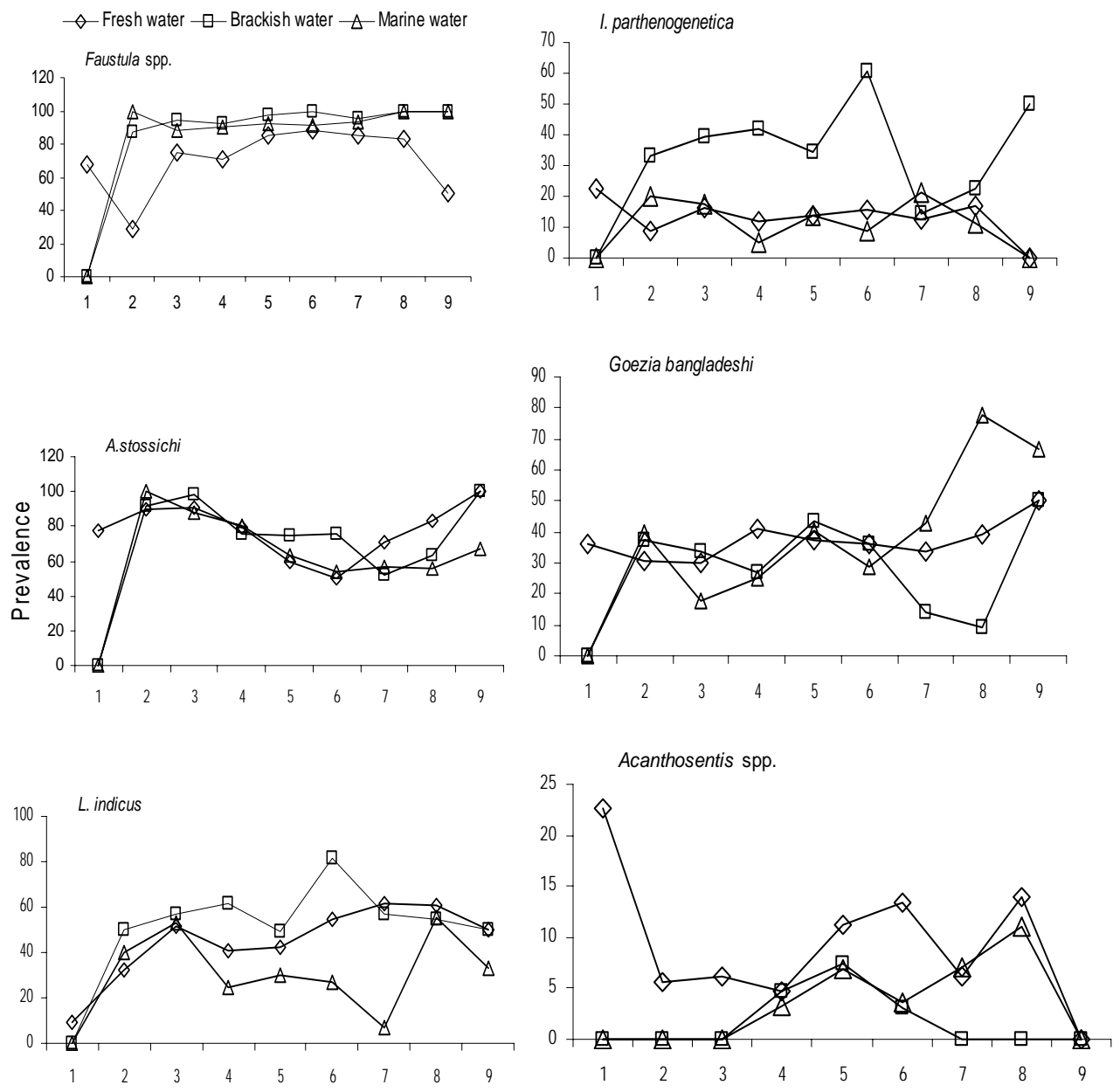

Length groups

Fig. 2. Prevalence of infection of component parasites in size classes of the hilsa.

A. stossichi: Higher prevalence was observed in larger and smaller size classes than that of in the middle classes in freshwater sample. Peak intensity $(95.41 \pm 128.1)$ was observed in middle group (6th gr) in freshwater hilsa. In brackish water sample both prevalence and intensity of infection by $A$. stossichi did not show relation with size of the host fish. Like freshwater sample peak prevalence was observed in the largest and smaller classes of brackish water T. ilisha. In marine hilsa, prevalence and intensity of infections were higher in smaller size classes except for second peak intensity in largest size class. 

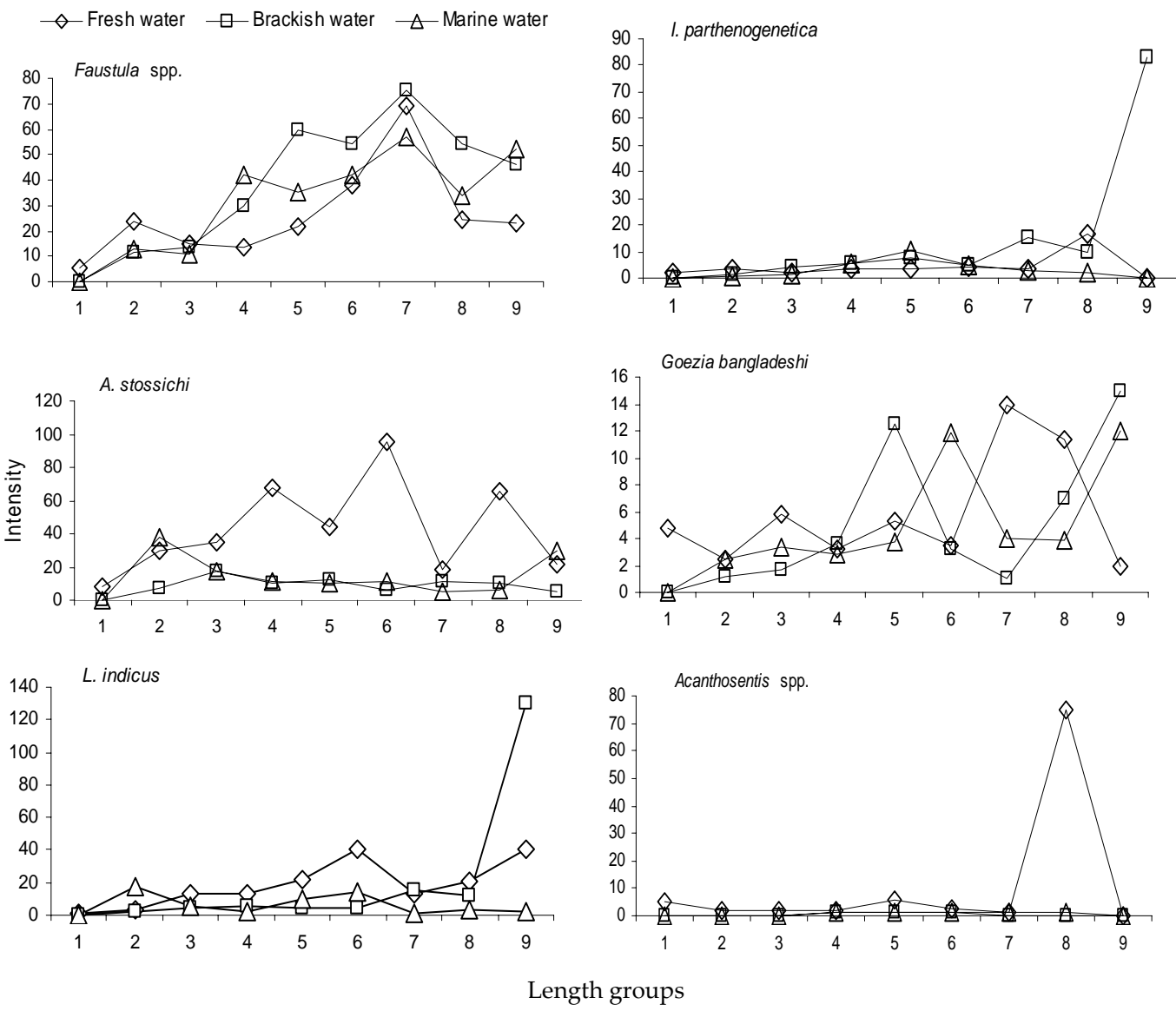

Fig. 3. Intensity of infection of component parasites in size classes of the hilsa.

L. indicus: Prevalence increased with size, though intensities did not show any relations with size of the $T$. ilisha in freshwater sample. Peak mean intensity (40.79 \pm 42.54) was observed in 6th gr and in the largest class (9th gr). In brackish water hilsa peak prevalence $(81.82 \%)$ was in the middle size class (6th gr) and in the other classes it was almost same. Only 2 fish fell in the largest size class one of which had 130 L. indicus individuals but other had none. In marine water samples both prevalence and intensity were irregular being peak prevalence in the 3rd gr and peak intensity in the 2nd gr.

G. bangladeshi: In freshwater hilsa no sharp peak prevalence was observed in any length groups. The intensities in 7 th $(14 \pm 9.04)$ and 8 th gr $(11.38 \pm 9.58)$ were considerably high. In brackish water hilsa highest prevalence $(50 \%)$ and intensity $(15 \pm$ 13.58) of infection was observed in largest length class. Lowest prevalence $(9.09 \%)$ was found in 8th length group and lowest intensity (1) in the 7th group. In marine hilsa peak prevalence was observed in size class prior to the largest (8th gr) and peak intensity in 
the largest size class (9th gr). Lowest prevalence (17.65\%) and intensity $(2.87 \pm 12.78)$ was observed in the smaller size classes (3rd and 4th, respectively).

Acanthosentis spp.: Highest prevalence (22.73\%) was observed in the smallest size class but highest intensity $(75.2 \pm 13.17)$ recorded in the largest class in freshwater hilsa. Smaller fish were more vulnerable to infection by Acanthosentis spp. and larger fish harbor more parasite individuals. One hilsa had 354 individual, which makes the intensity so high in this class. Intensities in other classes in freshwater hilsa were low and ranged from $1.2 \pm 12.59$ to $5.77 \pm 12.33$. In brackish water only a few Acanthosentis spp. was recorded which fell in the middle size classes (4th, 5th and 6th gr) with peak prevalence in 5th gr, intensity were almost equal in length classes. In marine water hilsa no Acanthosentis spp. was found in the smaller fishes (1st, 2nd and 3rd gr) and in the largest size class (9th gr). Highest prevalence (11.11\%) was observed in 8th class. Intensities were almost same in the other classes and it was close to 1 . This type of distribution indicated that the fish get infected in comparatively older age by these acanthocephalans.

I. parthenogenetica: Peak prevalence $(22.73 \%)$ was recorded in the smallest size class and peak intensity $(16.5 \pm 3.56)$ in the larger group (8th gr) of freshwater T. ilisha. In other size classes prevalence and intensity were almost same in freshwater hilsa. In brackish water peak prevalence $(60.61 \%)$ was observed in the middle size class (6thgr) and highest intensity $(83 \pm 8.92)$ in the largest size class. In marine T. ilisha prevalence of infection did not show any regular pattern with size of the fish. It was higher in both smaller and larger classes than in the middle classes. Highest mean intensity $(10.71 \pm 6.75)$ observed in one of the middle size class (5th gr).

Analysis of variance revealed that in freshwater hilsa differences between most of the lower groups were not significant at 5\% level. In brackish water hilsa parasite burden were significantly different between length groups. In marine hilsa mean parasites burden in different length classes were not significant at $5 \%$ level (Table 3 ).

In the majority of the parasites - host system analysed, there is a positive correlation between the abundance of parasites and host size. In some of them, the parasite is present from the lowest size class; in others there is a threshold size ${ }^{(12)}$. Prevalence and intensity in case of most of component parasites did not show any relation with host size of T. ilisha, i.e., distributions of these helminths are independent of size of host. Only the mean intensity of Faustula spp. and A. stossichi increased with size of the host to certain size classes and again declined in the largest size class. The rest of the component parasites did not show any pattern with host size (Fig. 1). While considering the groups of helminths only, trematodes showed significant positive correlation with weight and length. This trend in intensity was almost identical in the hilsa sampled from all the three habitats. Gorbunaova(13) distinguished parasites of Esox lucius and Rutilus rutilus into 3 groups: (a) parasites independent of age of host, (b) parasites decreasing in abundance 
with age of host; and (c) parasites increasing in abundance with age of host. Most internal helminths belong to the third group ${ }^{(14,15)}$. The parasites of T. ilisha belong to the first category. Among the factors that play a role in the increase in prevalence and intensity, an important influence is the amount of food consumed by the host ${ }^{(16)}$.

Table 3. Mean parasite abundance in length classes of hilsa in three ecological sites (ANOVA).

\begin{tabular}{|c|c|c|c|c|c|}
\hline \multicolumn{2}{|c|}{ Freshwater } & \multicolumn{2}{|c|}{ Brackish water } & \multicolumn{2}{|c|}{ Marine } \\
\hline Length groups & Means & Length groups & Means & Length groups & Means \\
\hline 1 st & $3.705 b^{*}$ & 1 st & No fish & 1st & No fish \\
\hline 2nd & $4.934 \mathrm{ab}$ & 2nd & $4.177 \mathrm{~d}^{*}$ & 2nd & $7.631 \mathrm{a}^{*}$ \\
\hline $3 r d$ & $5.932 \mathrm{ab}$ & $3 r d$ & $5.559 \mathrm{~cd}$ & $3 r d$ & $5.034 \mathrm{a}$ \\
\hline 4 th & $7.144 \mathrm{ab}$ & 4 th & $6.024 \mathrm{bcd}$ & 4 th & $6.130 \mathrm{a}$ \\
\hline 5 th & $6.031 \mathrm{ab}$ & 5 th & $8.143 b c$ & 5 th & $6.073 \mathrm{a}$ \\
\hline 6th & $7.646 \mathrm{ab}$ & 6th & $7.926 \mathrm{bc}$ & 6th & $6.374 \mathrm{a}$ \\
\hline 7th & $8.234 \mathrm{a}$ & 7 th & $8.456 \mathrm{~b}$ & 7 th & $6.484 \mathrm{a}$ \\
\hline 8th & $9.103 \mathrm{a}$ & 8th & $7.741 \mathrm{bc}$ & 8th & $7.657 \mathrm{a}$ \\
\hline 9th & $7.307 \mathrm{ab}$ & 9th & $12.325 \mathrm{a}$ & 9th & $8.214 \mathrm{a}$ \\
\hline
\end{tabular}

*Means followed by same letters are not significantly different at $5 \%$ level of significant.

The increase in the intensity of Faustula sp. and A. stossichi with age of the host may reflect a change in the diet of the host fish as they age. The presence of these parasites in smaller size classes (youngs/juveniles) suggests that fish may be infected on or relatively soon after leaving the nursery grounds and consistent level in other size classes indicate that the fish probably do not acquire these parasites in older age. Two types of digenea viz., fellodistomid (Faustula spp.) and hemiurid (A. stossichi and L. indicus) gain entry into host fish through its food ${ }^{(16)}$. The diet of T. ilisha is diverse, feeding on phytoplankton and large amounts of zooplankton such as copepods. The increase in mean intensity of parasites (Faustula spp. and A. stossichi) with size of host indicates that as T. ilisha grows older it feeds more voraciously.

Host diet, foraging strategy and habitat diversity are the three most basic factors affecting parasite communities in hosts. Generally large hosts have higher dispersal abilities than smaller fish. As fish size increases individuals may be expected to use more diverse habitats, and to forage in a wider range of places. Alternatively, different taxa of component parasites can response to the body size of host in different ways. This type of species-specific response of parasites to host body size was reported by Bell and Burt ${ }^{(17)}$. Characteristic types of life cycle of each parasites species may be the cause behind their dissimilar response to host size. 
Parasites may respond to its host size/age in different ways. Holmes ${ }^{(18)}$ observed relationship between a demographic parameter (prevalence/intensity/abundance etc.) of parasitism and the size of individuals of a particular host species: the invasion of a host population by an adult trematode follows a pattern related to age of individual hosts. Holmes ${ }^{(18)}$ adds, at birth, every demographic parameter is usually zero; later on, a helminthofauna is acquired, and one may imagine a series of different patterns.

In a survey on samples from natural populations, it is difficult to determine the causes of the observed variations. However, it is possible that all the parasites studied (though the life cycles are not well known) infect fish through ingestion of an intermediate host carrying the infective larvae. However, to relate the parasite burden in T. ilisha from different habitats, feeding of hilsa with respect to size and habitat need to be studied. From the site that hilsa will be sampled, the intermediate hosts also have to be assessed. These investigations will further clarify infection dynamics of parasites of $T$. ilisha.

\section{Acknowledgement}

This study was conducted under the NUFU-Hilsa Parasite Project financed by the Norwegian Council of Universities Committee for Development Research and Education (NUFU).

\section{References}

1. D' Silva J and SM Khatoon 1997. Helminth parasites of two clupeid fishes from the Bay of Bengal, Bangladesh. The Journal of NOAMI. 14(1\&2): 27-37.

2. Akther M, A Alam, J D'Silva, AI Bhuiyan, GA Bristow and Berland, B 2004. Goezia bangladeshi n. sp. (Nematoda, Anisakidae) from an anadromous fish Tenualosa ilisha (Clupeidae). Journal Of Helminthology 78: 105-113.

3. Bhuiyan AI 2006. Metazoan ectoparasites on the gills of the hilsa shad, Tenualosa ilisha. The Dhaka Univ. J. Biol. Sci. 15(1): 23-29

4. Bhuiyan, AI, J D'Silva, and GA Bristow 2007. The metazoan ectoparasite community on the gills of the hilsa shad Tenualosa ilisha (Clupeidae) in Bangladesh. The Dhaka Univ. J. Biol. Sci. 16(1): 1-10.

5. Bhuiyan AI, J D'Silva and GA Bristow 2009.. Parasites of Hilsa shad, Tenualosa ilisha in Bangladesh. Bangladesh J. Zool. 37(2): 221-230.

6. Snieszko SF 1983. Diseases of fishes: Research and control. Fisheries 8: 20-22.

7. Margolis L, GW Esch, JC Holmes, AM Kuris and GA Schad. 1982. The use of ecological terms in parasitology. (Report of an ad hoc committee of the American Society of Parasitologists.). J. Parasitol. 68(1): 131-133

8. Bush AO, JM Aho and CR Kennedy 1990. Ecological verses phylogenetic determinants of helminth parasite community richness. Evolutionary Ecology 4: 1-20. 
9. Berland B 1982. Basic techniques involved in helminth preservation. In Proceeding of workshop on "Technology as applied to museum parasite collections." ICOPA V-1982. Toronto, Canada: 1-15.

10. SAS Institute Inc. 1989. SAS/STAT user's guid, version 6, 4th ed. Vols 1 and 2. SAS Institute Inc., Cary, N. C.

11. Sures B, K Knopf, J Wurtz and J Hirt 1999. Richness and diversity of parasite communities in European eels Anguilla anguilla of the river Rhine, Germany, with special references to helminth parasites. Parasitology 119: 323-330

12. Saad-Fares A and C Combes 1992. Abundance/host size relationship in a fish trematode community. Journal of Helminthology 66: 187-192.

13. Gorbunaova MN 1936. Changes in the parasite fauna of pike and roach with the age of the host. Ann. Leningr. Univ. VII: 3-13.

14. Bauer ON. and NP Nikolskaya 1957. The dynamics of the parasite fauna of Coregonus lavaretus ludoga and its epizootological importance. Bull. Inst. Freshw. Fish. Leningr. XLII: 105-115.

15. Lawrence JL 1970. Effects of season, host age and sex on endohelminths of Catostomus commersoni. J. Parasitol. 56: 567-571.

16. Dogiel VA 1958. Ecology of the parasites of freshwater fishes. In Dogiel, Petrushevski and Polyanski (eds.): Parasitology of fishes. 1-47. Oliver \& Boyd, Edinburgh \& London.

17. Bell G and A Burt 1991. The comparasitve biology of parasite species diversity: Internal helminths freshwater fish. J. Animal Ecology. 60:1047-1063.

18. Holmes JC 1990. Helminth communities in marine fishes. In: Esch, G. W., Bush, A. O. \& Aho, J. M. (Eds). Parasite communities: patterns and process. London, Chapman and Hall. 101130. 